\title{
"Agroecologia em terras indígenas": das fronteiras da sustentabilidade à política de educação intercultural
}

\author{
Tércio Fehlauer* \\ Caroline Ayala**
}

\begin{abstract}
"A subjetividade da natureza, ainda aguilhoada, não poderá se libertar antes da comunicação dos homens entre si não estar livre da dominação" (Marcuse)
\end{abstract}

Resumo: A agroecologia, mesmo essencialmente crítica, vem manifestando limitações na relação com os povos indígenas. $\mathrm{O}$ desafio agroecólogico proposto para uma relação intercultural afirmativa diz respeito à superação das posturas etnocêntricas e hierarquizantes recorrentes em seus discursos. Neste sentido, a conformação da política pedagógica de um curso superior de agroecologia para indígenas (curso "Agroecologia em Terras Indígenas") vem possibilitar a criação de um espaço pedagógico intercultural que reconheça e compreenda as dinâmicas produtivas indígenas nos seus próprios termos e circunstâncias, libertos de determinismos conceituais e da imposição de grades interpretativas alheias. Esta premissa de conhecimento social passa a balizar a construção da sustentabilidade em Terras Indígenas e suas experiências.

Palavras-chave: Agroecologia indígena; sustentabilidade intercultural; etnodesenvolvimento.

\begin{abstract}
Agro-ecology, although essentially critical, is manifesting limitations in the relationship with indigenous peoples. The agroecological challenge proposed for an affirmative intercultural relationship refers to the over-action of ethnocentric and hierarchical attitudes recurring in their speech. In this way, the conformation of the pedagogical politics of a university course in agro-ecology for indigenous people (the course "Agro-ecology on Indigenous Land") is making possible the creation of an intercultural pedagogical space which recognizes and understands the indigenous productive dynamics on their own terms and in their own circumstances, free from conceptual determinisms and from the imposition of other interpretative restrictions. This premise of social knowledge underlies the construction of sustainability on Indigenous Land and through indigenous experiences. Key words: Indigenous agro-ecology; Intercultural sustainability; ethnodevelopment.
\end{abstract}

*Eng. Agr. Msc. Agroecossistemas, Pesquisador em "Agroecologia Indígena" da Agência de Desenvolvimento Agrário e Extensão Rural de MS (AGRAER). agroecologia@bol.com.br ** Antropóloga Msc., Analista em Reforma e Desenvolvimento Agrário do Instituto Nacional de Colonização e Reforma Agrária (INCRA), Superintendência de Mato Grosso do Sul. 


\section{Introdução}

$\mathrm{O}$ atual debate sobre sustentabilidade em Terras Indígenas tem colocado o campo científico da Agroecologia sob potencial de contribuição científica para o etno-desenvolvimento, amparado pelos objetivos de sustentabilidade social, ambiental e cultural propugnado na teoria agroecológica.

Destarte a amplitude destes objetivos e o desejo de constituição de uma epistemologia interdisciplinar, propomos neste texto uma reflexão sobre as fronteiras das relações que estão sendo assim constituídas na disciplina agroecológica, suas ambigüidades políticas e culturais. Para este propósito, esboçamos uma análise sobre as vicissitudes dos fundamentos "indígenas" da agroecologia, bem como de seus modos de inserção nos debates sobre interculturalidade, sustentabilidade cultural e, mais recentemente (em uma perspectiva aplicada), sobre educação e agroecologia em Terras Indígenas. A reflexão e as questões postas neste texto visam a constituir elementos propositivos para o debate sobre as condições e possibilidade de uma proposta de educação intercultural baseada na agroecologia.

\section{Agroecologia, povos indígenas e reminiscências colonialistas}

A disciplina científica da agroecologia tem como seu marco histórico de emergência o âmago da crise da ciência positivista. Desta forma, foi constituída essencialmente a partir da crítica da epistemologia ocidental clássica (em termos gerais, de conseqüência disjuntiva, utilitarista, tecnicista e homogeneizante). Este caráter crítico e auto-reflexivo delineou para a disciplina agroecológica um sentido fundamental de relativização da ciência ocidental, cuja conseqüência vem promovendo no âmbito científico agroecológico uma abertura político-epistemológica para as etnociências, conhecimentos "tradicionais" ou locais (ou "coevolutivos"). Levando este pressuposto ao limite, Norgaard (1989, p. 47) afirma que é justamente "as premissas de conhecimento cultural e coevolução que fazem única a agroecologia".

No entanto, passado este referencial dos marcos disciplinares da agroecologia e apesar da assumida identidade transformadora, em tese, muita coisa precisa ser confrontada, para que se possa propor escolhas e concepções alternativas de agroecologia que venham a ter consonância com as aspirações de participação intercultural, especialmente no quadro

34 Tércio FEHLAUER; Caroline AYALA. "Agroecologia em terras indígenas".... 
geral do debate (eminentemente antropológico) sobre o que vêm a ser estas "premissas de conhecimento cultural" e, sobretudo, "interculturalidade".

O pressuposto agroecológico de valorização do saber indígena, constatada recorrentemente nos discursos agroecológicos "clássicos" (Altieri, 1989; Guzmán Casado; González de Molina; Sevilla Guzmán, 2000), tem traduzido o reconhecimento geral na disciplina de que foi a partir dos "sistemas indígenas" que se obteve "grande parte da matéria prima para o desenvolvimento de hipóteses e de sistemas alternativos de produção na agroecologia" (Altieri, 1989, p. 38).

Contudo, para uma análise mais atenta deste ideal de "revalorização indígena", cabe questionar: que sentido a agroecologia vem atribuindo ao conhecimento indígena? (seria o de "matéria-prima" ou base exploratória e neocolonialista de nossa ciência, como sugere a referência acima em Altieri (1989)). Com efeito, de forma geral a literatura científica agroecológica trata a questão com uma generalidade que merece atenção. Vejamos alguns exemplos:

As sociedades indígenas portadoras de uma 'cosmovisão' (..) tem sua identidade situada em uma 'subsunção formal' porque suas formas de manejo possuem normalmente uma lógica ecológica de grande interesse para sua reprodução no contexto de 'novas tecnologias agroecológicas' (Guzmán Casado; González de Molina; Sevilla Guzmán, 2000, p. 188);

Os agroecólogos empenham-se em entender como os sistemas tradicionais se 'desenvolveram' para aprimorar a ciência da ecologia, de forma que a agricultura moderna possa ser feita de maneira mais sustentável (Nordgaard, 1989, p.47).

Este quadro epistemológico remete a Foucault (2005), quando trata das ambições totalizantes da ciência ocidental, operadas sobretudo por meio de anexações de outros discursos. Neste sentido, não obstante a legitimidade da agroecologia em defender e reinterpretar o conhecimento indígena em modelos de "ecologia cultural" aplicada à agricultura e julgar estas interpretações como significativas para a ampliação do horizonte explicativo da ciência ocidental e revisão interna de seus princípios epistemológicos, a ênfase da crítica em questão passa a ser no grau de reprodução externa da lógica científica ocidental (e sua "compulsão" totalizadora) e da extensão (aos modos de vida indígena) da cientificidade moderna. Assim, a disciplina agroecológica acaba por constituir, na sua gênese científico-ocidental, formas renovadas de autorepresentação de superioridade (mesmo que "alternativas") e de exercício de poder etnocêntrico. O modus operandi desta contradição se manifesta ao se imputar valor ao conhecimento indígena ao mesmo tempo 
em que transforma (e, portanto, "coloniza") a sua natureza, segundo normas e códigos generalizantes da própria ciência ocidental.

Contudo, a radicalização deste comportamento etnocêntrico que se instala na disciplina agroecológica ocorre com a conformação de discursos que reafirmam e renovam (sob outros termos) o postulado de superioridade científica ocidental de acesso a uma suposta "verdade", que acabam por recuperar os próprios fundamentos da filosofia do progresso (cujo império é a antítese do conhecimento cultural e do reconhecimento das diferenças).

Estes discursos de "verdade" (a exemplo de Caporal, 2004; Costabeber, 2002; Sevilla Guzmán; González de Molina, 2005) de natureza essencialmente política e hierarquizante, nesse entendimento, sobrepujam aspectos éticos primordiais e afastam-se do debate atual da antropologia (comprometendo, no seio da agroecologia, a tese da interdisciplinaridade). Os seus agentes acabam manifestando o que Bourdieu (2005, p. 85) denomina de "rupturas falsamente revolucionárias", conformando interesses e modos estratégicos particulares de acumulação de capital simbólico no panteão científico atual, sobretudo por meio de exibicionismos retóricos, sem se perguntar pelas condições sociais de sua gênese. Estes, de maneira geral, avessos à reflexão sobre alteridade (perspectiva antropológica), tendem mais facilmente a enquadrar a análise dos povos indígenas no estatuto geral da desigualdade e exclusão (perspectiva sociológica, normalmente de raiz marxista). Deste modo, mesmo que não intencionalmente, acabam por reforçar as hordas do assistencialismo e do "parcipativismo" instrumental (Ayala; Fehlauer, 2005).

\section{Para uma agroecologia indígena: a crítica da crítica}

O caráter crítico da agroecologia vem permitindo certa consonância entre seus pares em relação à inclusão de uma dimensão cultural intrínseca ao conceito de sustentabilidade, tratado nos termos de "um sentimento social acerca da agricultura" (Noorgaard, 1989, p.28). Este princípio de "sustentabilidade cultural", como o visto, adquire grande valor na conformação identitária da agroecologia ao flexibilizar fronteiras disciplinares e, por conseguinte, ampliando horizontes de estudos para além das ciências naturais, ao presumir o diálogo com as ciências humanas.

Contudo, se a crítica cultural significou a definição de um ponto de partida transformador para a prática científica agroecológica, a mesma crítica (como numa armadilha) ao criar "a aparência de uma distância 
no seio da própria pertença" (Certeau, 2005, p. 105) pouco mudou o seu funcionamento (e racionalidade). Em outras palavras, o "sentimento" social confunde-se com o "sentimento crítico", gerando a transfiguração prática e teórica da agroecologia em uma égide moral de "novo profissionalismo", expressão recorrente em Chambers (1983, p. 29, 53), Caporal (1998, p. 11, 21, 270, 369, 474) e Caporal; Costabeber (2000, p. 03,05 e 20). Seus agentes, antes de refletirem sobre seus limites, direcionam assim todos esforços na afirmação política diferencial desta "verdade" (e seus ganhos ostentatórios).

Neste sentido, a análise das "fronteiras" da sustentabilidade cultural desafia a disciplina agroecológica e seus agentes, sobretudo, a decifrar o seu próprio lugar (onde faz seus enunciados e interpretações), tornandose a condição e possibilidade para interculturalidade e o reconhecimento, de fato, das diferenças. Conforme assevera Certeau (2003, p. 167),

toda ciência [que se quer] humana deve introduzir a suspeita em seu próprio desenvolvimento para interrogar sobre sua relação histórica com um tipo social. Ela está vinculada a uma forma de cultura. Para se definir novamente, deve fazer uma análise contestadora da civilização que ela postula.

Esta contestação, contudo, não se reduziria a uma moral e normativa do reconhecimento do cultural e da existência das diferenças. Não se pode crer que alguém, um dia, não soube disto (embora seja comum sua dissimulação). A questão, para além da "boa" moral (ou "chamados à ordem"), exige da agroecologia determinadas apreensões que as ciências humanas há tempo propõem e que só é possível perceber na medida que nos destituirmos (enquanto cientistas ocidentais) da crença em uma condição de observador universal, aquele que pensa ver o mundo como ele "é". Dentre estas apreensões, as questões: em nome do quê se declara o "diferente" em outra cultura? De onde, de que outro lugar se realiza a sua análise e apreensão?

Por outro lado, na medida em que definimos nossas ações como expressão cultural (e não mais produto de um observador "neutro" e objetivo) passa-se a admitir um referencial. A diferença que percebemos em relação ao "outro" teria por referência, portanto, a uma particular perspectiva de ver, sentir e perceber o mundo. Portanto, se a pretensão é conhecer o outro (e suas diferenças), primeiramente precisamos compreender como conhecemos, ou seja, quais os postulados de nossa forma de conhecer (nossa etnoepistemologia ocidental). Para Merleau-Ponty (2003, p. 23), "o pensamento precisa encarar a gênese do seu próprio sentido".

A interrogação deste sentido que dá forma ao nosso conhecimento, passa a ser o fundamento reflexivo necessário à agroecologia a fim de 
que não se recorra, via naturalização do seu pensamento, à renovação de velhas formas de colonização cognitiva e epistemológica (um certo tipo de "colonialismo intelectual") ${ }^{1}$.

Uma das formas clássicas desta colonização diz respeito a modos de análise da atividade agrícola dissociada de seus fundamentos sociais, afetivos, práticos e expressivos (sua base relacional e contextual) para conformar abstrações analíticas cujas características recorrentes transformam o cotidiano prático agrícola em modelos que os povos nativos acabam por não se reconhecerem neles. Segundo Bourdieu (2005), o erro metodológico acontece ao se tomar as construções que o cientista produz para entender as práticas, para explicá-las, como se fossem os princípios determinantes destas práticas. Apesar dessa base crítica, também o agroecológo, ao realizar a clássica operação (estilo "farming systems"), tende a ver todos os agentes sociais (e suas práticas) à sua própria imagem, transformando o "outro" no "mesmo" (articulando, ao seu modo, o poder homogeneizante da ciência). No ponto de vista do debate da interculturalidade isto vem significar a imposição do postulado científico ocidental da intrínseca superioridade teórica sobre a prática, que desde Bacon, realiza a colonização das artes e ofícios cotidianos em nome de conceitos e formalismos teóricos e disciplinares ${ }^{2}$.

Todavia, como o visto, a agroecologia tem concorrido para a crítica do império tecnocrático, o que de certa forma, vem definindo um espaço de experiência e de superação do conservadorismo de suas agendas ocultas (intelectualizante, (neo)positivista, escolástica). No sentido da radicalização desta crítica é que se propõe, para além da conformação da agroecologia por meio de discursos e enunciados eloqüentes (fonte inconteste de preconceitos), elementos para uma agroecologia indígena que, através da necessária relativização científica para a interculturalidade, venha a realizar experiências práticas de construção do conhecimento que abordem, sobretudo, as práticas nas próprias práticas ordinárias e cotidianas indígenas. Abdica-se assim, na própria interação intercultural para o conhecimento, do desejo e do exercício de poder etnocêntrico de "dominar as práticas com o olhar", transformando-as em representações e categorias científicas ${ }^{3}$.

Muitos estudos, dos quais destacamos Overing (1999) junto aos Piaroa (Amazônia brasileira), Passes (2000) com os Palikur (Amazônia guianense), Fehlauer (2004) com os Terena (Bacia do Alto Paraguai sulmato-grossense) e Richards (1995) no caso dos Mende (África ocidental) estão orientadas por uma abordagem que considera aspectos práticos e expressivos da agricultura indígena, sem dissociá-los da rede relacional

38 Tércio FEHLAUER; Caroline AYALA. "Agroecologia em terras indígenas".... 
em que estão imbricados. A ênfase passa a ser no conhecimento dos auspícios sob os quais as atividades agrícolas realizam-se em suas bases nas relações sociais, políticas e ambientais do cotidiano local indígena ${ }^{4}$.

Na linha deste conhecimento cultural, de base etnográfica, é que se propõe como premissa de uma agroecologia indígena, o conhecimento das vivências e dos modos indígenas de sustentação, formas de organização social e política, incluindo modos de produção, consumo, troca e padrões locais de sustentabilidade.

\section{Curso superior "Agroecologia em Terras Indígenas": deslocamentos conceituais e desafios político-educacionais para a interculturalidade}

No contexto do debate sobre as bases epistemológicas da agroecologia e os dilemas e anacronismos relativos à apreensão de alteridade nos fundamentos da disciplina agroecológica, vem sendo construída a proposta de curso superior "Agroecologia em Terras Indígenas" 5 .

Não obstante os desafios desta construção de relativização científica para a interculturalidade, algumas tensões nela subjazem, especialmente em relação à superação de posições (as quais entendemos como) preconceituosas quanto às possibilidades interculturais da agroecologia.

Embora a legitimidade da preocupação em relação aos riscos de iniqüidade nas relações de poder estabelecidas e consequente imposição do paradigma científico ocidental (recorrente na história do contato interétnico e colonizador) por meio da agroecologia, repete-se o erro quando, por mera antítese dualista- reforça a égide da ciência ocidental como algo monolítico e ahistórico, necessariamente de natureza, positivista e prescritiva. Em outros termos, ante o entusiasmo ideológico do cientificismo, muitos de seus opositores respondem com uma mera recusa. Com efeito, recusa que não é o caso aqui. Em concordância com Velho (2001), a mera recusa, na verdade, vem confirmar o cientificismo, por ignorar, paradoxalmente e no mesmo movimento, o diagnóstico da grande crise que vive a ciência e o cientificismo.

Nesta (e através desta) crise da ciência moderna, muitos debates se colocam no cerne das disciplinas científicas que, lançando contra seus limites (que é que se propõe), vem proporcionando elementos para repensar a prática científica para além do jogo ideológico de poder, ou seja, que venha permitir uma prática científica não identificada a essas imagens ideologicamente poderosas e etnocêntricas. Em suma, a crítica da ciência ocidental e a agroecologia "clássica" (como seu apêndice) não 
implica, como poderia sugerir um observador menos atento, uma ruptura com a ciência, ou um postulado anti-científico. Isto significaria ignorar a crise na ciência e o despertar de novas bases científicas não positivistas. O que se postula aqui é justamente este contraponto e a constituição destas novas condições de possibilidade para a agroecologia, especialmente por meio da sua experiência intercultural.

Neste sentido, em relação à apreensão conceitual de agroecologia (fundamento para a conformação identitária do curso em pauta), antes de a admitirmos em uma estética positivista ou restrita a construção linear de uma crítica de modelos de agricultura, especialmente no contexto intercultural, havemos de também lançá-la contra seus limites, refletindo nas suas raízes conceituais e etimológicas do "agro" e da "ecologia".

Com relação ao conceito de agricultura ("agro") assenta-se "conservadorismos" conceituais que merecem ser relativizados. Vinculado à história do ocidente, a agricultura tornou-se cada vez mais percebida como categoria subsidiária da teoria econômica, e tende, por conseguinte, a ser interpretada como uma atividade exclusivamente relacionada à produção e atendimento às necessidades materiais de um grupo social, ou seja, apresenta uma premissa de registro em uma ordem funcionalista e utilitária (relacionada à supremacia do pensamento econômico). A essência de realização cultural e expressiva (o "ser") da agricultura fica reduzida a meros mecanismos técnicos de obtenção de satisfação material (o "ter") ou sobrevivência de um grupo social.

A agroecologia "clássica", mesmo crítica do produtivismo e preconizadora de princípios sistêmicos na abordagem das atividades agrícolas nativas, ao incorporar nos seus esquemas explicativos elementos da organização social, valores e lógicas nativas, mesmo assim acaba- como tendência interpretativa- por tomá-los como subsidiários hierarquizados na análise do "agro", conformando dimensões que gravitam sob seu centro explicativo. A "tradição" desta abordagem, vem sugerindo um sentido e uma proposição de análise do "agro" como "geração [interpretativa] de uma estrutura de funcionamento da exploração agrícola de um grupo social" (Guzmán Casado; González de Molina; Sevilla Guzmán,, 2000, p.175). Assim, sub-repticiamente, se faz retornar a lógica da economia ocidental (mesmo em outros termos) pelo paradigma político do privilégio da análise estrutural em detrimento da agência nativa (tornada invisível no universo da nova codificação que se generaliza).

No entanto, o "sentimento" social que se postula como diferencial ético agroecológico, ressurge aqui na definição de um espaço reservado 
ao nativo. Este espaço de participação nativa, normalmente marcados por expedientes de "condescendência" (Bourdieu, 1989, p. 128), se efetivam por meio de "tecnologias de participação" ou da aplicação de "metodologias participativas", normalmente colocadas no limite da linguagem, do diálogo e da organização- categorias críticas no debate sobre antropologia do desenvolvimento (Hobart, 1995, Gallois, 2001, dentre outros), e naturalizadas (inquestionadas) no discurso agroecológico instrumental ${ }^{6}$.

A relativização destas apreensões do "agro" adquire evidência justamente no contexto intercultural. Como imaginar que categorias ocidentais como "agricultura", "economia", "trabalho", " produção", “ambiente" e "participação" tenham para outras culturas o mesmo significado, ou mesmo, tenham aí sentido?

No caso específico da categoria "agricultura", Passes (2000), em pesquisa com os Palikur (Amazônia guianesa), exalta a dimensão social e expressiva do "trabalho" agrícola Palikur, especialmente relacionada ao cultivo de mandioca. Nele, argumenta o autor, "trabalho" e "conversa" (entendida também como lazer, criação, convívio e personalidade) são aspectos integrais e gerativos de um preciso estado de convivialidade e socialidade geral expressada pelo processo de trabalho tanto de cultivo quanto de processamento da mandioca (rejeitando na origem a distinção cartesiana entre sensação e intelecção). A prática agrícola Palikur, vem consagrar à sua maneira, o postulado de que, de maneira geral, nas sociedades indígenas vida social, cosmologia e vida do trabalho não se distinguem (ao menos do modo como nós a distinguimos). O que sugere uma impropriedade perceber a agricultura como uma dimensão da vida social indígena, pois ela, normalmente, é a vida social.

Neste sentido, uma perspectiva intercultural da agroecologia ou uma agroecologia indígena conforme o propugnado para o curso em pauta deve refletir sobre as condições de validade, históricas (anacronismo) ou sociais (etnocentrismo) de conceitos - como o de agricultura - que parecem ter validade universal, quando, na realidade, são produtos de condições específicas (cuja especificidade muitas vezes nos escapa).

Do mesmo modo que o prefixo "agro" carrega discordâncias semânticas, na constituição da agroecologia- exceto para aqueles que desejam transformar a disciplina em propriedade- o sufixo "ecologia" também sugere tensões e deslocamentos conceituais.

O campo científico da ecologia tem suas origens nas ciências naturais, porém mais recentemente estas fronteiras estejam sendo flexibilizadas 
ao incorporar subdisciplinas como, por exemplo, ecologia humana e psicologia ecológica. Contudo, a estas transformações subjazem anacronismos e conflitos teóricos radicais. Em termos gerais, a ecologia guarda correspondência ao conceito ocidental de "natureza". Embora o pensamento ecológico seja, normalmente, crítico à objetificação da naturezalógica burguesa que promoveu e promove sua transfiguração como recurso natural (fonte de riqueza material)- sua identificação como campo científico se valeu de um conceito "irmão", a objetivação da natureza, tornada um princípio de realidade transcendente ${ }^{7}$. A esta realidade transcendente que se imporiam leis, poderes e energias por meio dos quais 0 mundo natural (na forma de "ecossistema"), adquire razão e pode ser explicar cientificamente. Deste modo, anacronicamente, retorna o clássico gesto cartesiano que transforma os fenômenos manifestos do mundo físico como instâncias subscritas ao processo da razão. Definições clássicas de agroecologia têm colocado hegemonicamente a agroecologia nesta perspectiva:

agroecologia corresponde a um campo de estudos que pretende o manejo ecológico dos recursos naturais, para- através de uma ação social coletiva de caráter participativo, de um enfoque holístico e de uma estratégia sistêmica- reconduzir o curso alterado da coevolução social e ecológica, mediante um controle das forças produtivas que estanque seletivamente as formas degradantes e expoliadoras da natureza e da sociedade (Sevilla Guzmán; González de Molina, 2005, p. 32)

Analisando sob o ponto de vista da interculturalidade, a naturalização de conceitos e abstrações teóricas como "recursos naturais", "participação", "coevolução", "seleção", "formas degradantes" e especialmente, "controle" merecem ser problematizadas. Contudo, para além da mera problematização e conseqüente (e sempre problemática) afirmação do racionalismo crítico para dentro de um curso indígena, exige-se a percepção de outras concepções de ecologia- por sob e além da égide hegemônica das ciências naturais- nas quais ecossistema não pode ser basicamente descritivo (transcendente) mas performativo. Neste sentido, o conceito ecologia não corresponde simplesmente a um esquema teórico pelo qual o mundo pode ser analisado e melhor administrado (ecologia gestionária). Ele passa a ser visto como um elemento deste mundo, ou seja, só faz sentido na interação- exige envolvimento experiencial ${ }^{8}$. Deste modo, abstrações analíticas independentes do contexto, mesmo quando falam de "ecologia", passam a ser "anti-ecológicas", pois remetem à "anti-ecologia" de determinismos diversos (técnicos, teóricos, conceituais, etnocêntricos, antropocêntricos, geográficos, políticos, dentre outros usuais).

42 Tércio FEHLAUER; Caroline AYALA. "Agroecologia em terras indígenas".... 
Nesta perspectiva, o curso "Agroecologia em Terras Indígenas" emerge como um espaço para uma experiência prática nessa ecologia alternativa que junta ação e intenção humana dentro de um dinâmico contexto (constituído mutuamente entre pessoas e seu ambiente). Neste sentido, sob o ponto de vista da definição de políticas pedagógicas condizentes com o propósito ecológico de consonância a realidade vivida pelos povos indígenas de MS, antes de reproduzir estratégias tecnocráticas segundo modelos abstratos, o que se propõe é trilhar um caminho de uma nova técnica que, segundo Certeau (2005) consiste em reconduzir as práticas e as línguas científicas para o seu país de origem, a vida cotidiana.

Nesta agroecologia as experiências de aprendizagem sobre sustentabilidade agroecológica das Terras Indígenas remetem, portanto, ao esforço de correspondência à interação cotidiana e aos próprios processos "nativos" de aprendizagem, onde, de maneira geral, aprender não é somente adquirir habilidades específicas (científicas), mas habilidades mais gerais que permitam incrementar a participação de todos envolvidos em comunidades de prática (contextos de vida), ou seja, onde o aprendizado é tido mais como um processo de atividade social do que um processo cognitivo (stricto senso).

O curso, na linha que está sendo proposto, pretende ser educacional ao tratar de uma exigência de conhecimento, mas não mais por meio do desejo de domínio, ou seja, conhecimento como exercício de poder e distanciamento social. Ao contrário, nesta nova acepção, o curso para ser ecológico e intercultural, ao estudar a realidade, deve fazê-lo sem julgamentos a priori de valor e, principalmente, buscar a compreensão daquilo que nela se faz e se cria. Em outras palavras, ao se permitir a percepção das múltiplas "maneiras de fazer" (Certeau, 2005, p.27) de um povo, pode-se, antes de qualquer julgamento, eventualmente descobri-las como saídas possíveis (e inteligentes) que, em dado momento, encontram os sujeitos que nele trabalham, estudam e, sobretudo, vivem.

Desta forma, para ser culturalmente afirmativo (e ecológico) hão de se enfocar as múltiplas criações da vida social indígena e compreender os modos como estas se realizam, locais e formas de credibilidades emergentes, esquemas operacionais, rede de trocas e relações pessoais, enfim, compreender os auspícios do vivido (seu "estado de arte") ${ }^{9}$. Somente com esta compreensão, situados neste contexto, poderão - estudantes e pesquisadores - modestamente contribuir, enriquecendo experiências, também situadas e controladas pelas pessoas da própria "comunidade". 
O curso "Agroecologia em Terras Indígenas" conduz, portanto, à vontade de conhecimento geral do cotidiano das aldeias, suas formas de apropriação e reapropriação, suas trajetórias (moldadas no fluxo dos acontecimentos) e de suas condições de possibilidade. O sentido desta aprendizagem e conhecimento, não mais como vontade de poder individualizante (e elitizante), mas um esforço de busca de credibilidade, identificação, confiança e realizações por dentro das vivências e do fluxo de vida cotidiana dos povos indígenas envolvidos (uma forma de engajamento). Esta agroecologia indígena não precisa, portanto, de máximas para sustentá-la, mas de realizações.

\section{Considerações Finais}

A competência da agroecologia no sentido de consubstanciar seus princípios críticos, para além da crítica que só reforça e esconde a própria pertença, exige que se questione: como vencer a hierarquização social que organiza o trabalho científico agroecólogico sobre as culturas indígenas e ali se repete?

Assim, o dilema epistemológico da agroecologia perfaz o movimento de uma disciplina que encontra grandes dificuldades de libertação do colonialismo, o qual resiste nela opela imposição tanto de abstrações e generalidades conceituais (sustentabilidade, holismo, complexidade, sistemismo, dentre outras) quanto de esquemas interpretativos relacionados às grandes narrativas da modernidade (como, por exemplo, o marxismo e o positivismo). O sentido proposto a este movimento está, sobretudo, no avanço da agroecologia na perspectiva da comunicação intercultural, colocando seus agentes em contato com as redes sociais e vivências cotidianas destes "outros" (em seus próprios termos), conformando desta maneira as bases para as condições compreensivas e interculturais da agroecologia.

Neste sentido, a criação de espaços experienciais e de aprendizagem, como a proposta de curso superior "Agroecologia em Terras Indígenas" pode permitir que estas percepções e teorias da ação se tornem práticas efetivas, princípio para a incorporação e consolidação de políticas pedagógicas interculturais engajadas na autonomia, sustentabilidade e liberdade - dos povos indígenas.

A meta do movimento agroecológico - nesta perspectiva ética alternativa - colocada então no sentido de mobilizar potencialidades antropológicas para o etnodesenvolvimento e sustentabilidade indígena. Para

44 Tércio FEHLAUER; Caroline AYALA. "Agroecologia em terras indígenas".... 
além do esforço de adequar procedimentos técnicos para a sustentabilidade ambiental das práticas agrícolas indígenas, as experiências geradas procuram na diversidade das práticas culturais, os contornos das formas de relações e modos desejados de convivência num ambiente indígena específico.

Milton (1996, p. 27), corroborando neste movimento, afirma: "se a cultura é o mecanismo através do qual os seres humanos interagem com seus ambientes, então a sobrevivência humana pode depender, em última estância, à diversidade cultural".

\section{Notas}

${ }^{1}$ De maneira geral (dada a sua complexidade), pode-se tratar esta temática nos termos da abordagem de um certo "estilo cognitivo ocidental". Este "estilo" tem sido tratado nas ciências humanos em geral sob vários predicados: intelectualizante (Richards, 1995), descontextualizante (Hornborg,1996), racionalizante e teleológico (Habermas,1988), formuláico (Richards, 1995) , de "espírito calculante" (Bourdieu, 2005, 179), Estrutural (Giddens, 1979), utópico (Lins Ribeiro, 1991), escriturístico (Certeau, 2005) e normativo-elitista (Foucault, 2005). Na prática, este "estilo" conforma uma ordem organizada pelo poder do saber científico ocidental. Define, nos termos de CERTEAU $(2005,92)$ "estratégias tecnocráticas que visam a criar lugares [disciplinas] segundo modelos abstratos", separando as línguas "artificiais" que articulam os procedimentos de um saber especificado e disciplinar e as línguas "naturais" que organizam a atividade significante comum cotidiana. Contudo, não se trata somente de modelos teóricos, mas da própria raiz da nossa ontologia- vinculada ao postulado de supremacia da razão e do império humano sobre a natureza (e as circunstâncias).

${ }^{2}$ Segundo RICHARDS (2001), este processo histórico de "colonização intelectual" é operado racionalmente por meio de uma confusão básica entre intenção e resultado no seio da prática técnico-científica e educacional em geral. Em um exemplo clássico, Bourdieu (1977), estudando os agricultores da etnia Berber da África meridional, mostra que o calendário agrícola destes povos não é, como se poderia pensar, um tipo de molde sazonal que guiaria a decisão do que fazer na agricultura, mas, sobretudo, um produto do processo de fazer decisões. O que quer dizer que, se extensionistas-educadores abordassem estes agricultores para uma participação em um tipo de "dia de campo" e apresentassem em uma lousa o que entendem ser o calendário agrícola Berber, estariam fazendo uma grande confusão, uma vez que, segundo o autor, estas pessoas vêem o calendário como resultado do que fazem (e não como seu guia). Em suma, para aprender adequadamente conhecimento indígena, como no exemplo da sazonalidade agrícola dos Berber, não podemos, de partida (como na abordagem convencional), realizar uma separação radical entre estrutura e ação (teoria e prática) para poder imputar precedência da primeira sobre a segunda, mas compreender que este conhecimento emerge por engajamento prático no mundo e como resultado deste, traduzido no aprimoramento da habilidade 
prática e criativa do viver. Portanto, implausível nos termos de uma "independência epistêmica" intelectual, uma mera intenção.

${ }^{3} \mathrm{O}$ que não implica a adesão ao puro empirismo, mas em incorporar uma nova teoria da prática (Bourdieu, 2005) na qual o princípio dicotômico teoria versus prática (idéia central do racionalismo ocidental) perde sua força ideológica. $\mathrm{Na}$ prática científica isto vem significar uma recusa a que se realize o corte que faz das práticas objetos de saber (separado da linguagem- e da inteligência- de seus procedimentos).

${ }^{4}$ RICHARDS (1995, p. 61) sugere pensarmos agricultura e conhecimento agrícola indígena como "performance social", habilidades gerais de uma "comunidade de prática", em sua maior parte destituídas da independência epistêmica (e, portanto, do intelectualismo) a qual a imputamos mesmo na forma de "conhecimento tradicional". Por conseguinte, a imposição da análise e de processos de formalização científica não corresponde, em tese, ao senso prático pelo qual o agricultor indígena realiza a ação (embebida num contexto social com sua própria lógica e imperativo cultural). Como resultado deste provável erro desvelam-se desencontros comunicativos e, muito freqüentemente, alimentam preconceitos engendrados pelas próprias conotações individualistas e abstratas de conhecimento.

${ }^{5} \mathrm{O}$ curso é uma convergência de esforços dos povos indígenas Terena e Kadiwéu de MS, juntamente com a Universidade Católica Dom Bosco (UCDB) e parceiros interinstitucionais dos Governos estadual (Agência de Desenvolv. Agrário, Assist. Técnica e Ext. Rural de MS-AGRAER) e Federal (Programa Pantanal/Ministério do Médio Ambiente; Ministério da Educação; CNPq-Ministério de Ciência e Tecnologia e PPIGRE-Ministério do Desenvolvimento Agrário). Para mais informações sobre o projeto e elementos de sua estrutura político- pedagógica vide "documento-base" do curso ou contate o NEPPI (Núcleo de Estudos e Pesquisa sobre Populações Indígenas) da UCDB no portal www.neppi.org.

${ }^{6}$ Vide Caporal; Costabeber (2004)

${ }^{7} \mathrm{O}$ movimento de objetivação da natureza, de origem religiosa, surgiu da idéia da natureza como um domínio tirado da humanidade (a expulsão do homem de seu paraíso) para, assim, poder estar submetida a seu império. Cabe registrar a correlação direta desta gênese cultural e civilizatória do ocidente com a atual crise ecológica mundial.

${ }^{8} \mathrm{O}$ conceito experiência adquire aqui um sentido além do senso comum como ao modo de um acúmulo de aprendizado prático. À noção de experiência incorporamse aspectos de cognição, afeto e volição e um sentido fenomenológico das emoções e do pensamento que, para além de adjetivos estáticos e da razão pura, vêm conformar formas de vidas humanas expressivas e circunstanciadas (Fehlauer, 2004).

${ }^{9}$ Neste ponto assenta-se a grande distinção política em relação às práticas colonialistas e suas novas versões. Nestas os povos indígenas são percebidos, ao contrário de afirmação, pela negativa, pelo "critério da falta" (CLASTRES, 1982). Estas perspectivas, normalmente ocultas, revelam uma teoria da ação bastante contestada na antropologia atual (grosso modo: "as pessoas agem pelo que elas são não pelo que não são"). A abordagem resultante deste "paradigma da escassez" leva peremptoriamente à subestimação da capacidade dos agricultores indígenas a resistirem às dificuldades, bem como de tratarem o modo pelo qual eles tentam 
supera-las como estratégias de "conseguir a qualquer jeito" ("muddling through") e não como a realização de inteligências e habilidades performáticas (Richards, 1995).

\section{Referências}

ALTIERI, Miguel. Agroecologia: as bases científicas da agricultura alternativa. Rio de Janeiro: PTA/FASE, 1989.

AYALA, Caroline; FEHLAUER, Tércio. Considerações críticas sobre o conceito etnodesenvolvimento: para pensar a condescendência na relação intercultural. $R e$ vista Tellus. Campo Grande: Editora UCDB, ano 5, n. 8/9, p. 37-49, abril/out, 2005.

BOURDIEU, Pierre. Outline of a Theory of Practice. Crambridge (R.U): Cambridge

University Press, 1977.

BOURDIEU, Pierre. Coisas Ditas. São Paulo: Brasiliense, 1989.

Razões Práticas. Campinas, SP: Papirus, 2005.

CAPORAL, Francisco Roberto. La Extensión Agraria del sector público ante los desafios del desarollo sostenible: el caso de RS, Brasil. 1998. Tese (Doctorado Agroecologia, Campesinato e Historia) - ETSIAN/Universidad de Córdoba, Córdoba, 1998.

CAPORAL, Francisco Roberto; COSTABEBER, José Antônio. Agroecologia e Desenvolvimento Rural Sustentável: Perspectivas para uma Nova Extensão Rural. Revista Agroecologia e Desenvolvimento Rural Sustentável. Porto Alegre, v.1, n.1, p.16-37, jan./ mar. 2000.

A análise multidimensional da sustentabilidade: uma proposta metodológica a partir da Agroecologia. Revista Agroecologia e Desenvolvimento Rural Sustentável. Porto Alegre, v.3, n.3, jul-set, 2002.

IICA, 2004.

A Agroecologia: alguns conceitos e princípios. Brasília:MDA/SAF/DATER/

CERTEAU, Michel de. A invenção do cotidiano 1: Artes de fazer. Petrópolis: Vozes, 2005.

A cultura no plural. Campinas: Papirus, 2003.

CHAMBERS, Robert. Rural Development: Putting the Last First. London: Longman, 1983.

FEHLAUER, Tércio. Conhecimento Indígena em perspectiva: performance, habilidades e capacidades agrícolas dos Terena da aldeia Limão Verde (Aquidauana-MS). 2004 Dissertação (Mestrado em Agroecossistemas) - PGA/UFSC, Florianópolis, 2004.

FOUCAULT, Michel. Microfísica do Poder. Rio de Janeiro: Edições Graal, 2005.

GALLOIS, Dominique Tilkin. Sociedades indígenas e desenvolvimento: discursos e práticas, para pensar a tolerância. In: GRUPIONI, Luis Donisete; VIDAL, Benzi Lux; FISCHMANN, Roseli (Orgs). Povos indigenas e tolerância. São Paulo: Edusp, 2001.

GIDDENS, Anthony. Central problems in social theory: Action, Structure and Contradiction ins Social Analysis. London: Macmillian, 1979. 
GUZMÁN CASADO, Glória; GONZALEZ DE MOLINA, Manuel.; SEVILLA GUZMÁN, Eduardo. Introducción a la Agroecologia como Desarrollo Rural Sostenible. Madrid: Ed. Mundi-Prensa, 2000.

HABERMAS, Jurgen. Ciência e técnica como ideologia. Lisboa: Edições 70, 1988.

HOBART, Mark. Introduction: the growth of ignorance? In: HOBART, Mark (org.) An Anthropological Critique of development. London and New York: Routledge, 1995.

HORNBORG, Alf. Ecology as semiotics: outlines of a contextualist paradigm for human ecology. In: DESCOLA, Philippe, PÁLSSON, Gisli (orgs.). Nature and Society. London: Routledge, 1996.

LINS RIBEIRO, Gustavo. Ambientalismo e desenvolvimento sustentado. Nova ideologia/ utopia do desenvolvimento. Revista de Antropologia. São Paulo, v.34, 1991.

MERLEAU-PONTY, Maurice. O visivel e o invisível. São Paulo: Perspectiva, 2003

MILTON, Kay. Ecologias: antropologia, cultura y entorno. Revista Internacional de Ciências Sociales 154, 1996. Disponível em: <http:/ / www.unesco.org/issj/rics154/ miltonspa.html>. Acesso em: 07 nov. 2003.

NORGAARD, Richard. A Base Epistemológica da Agroecologia. In: ALTIERI, Michel. Agroecologia: as bases científicas da agricultura alternativa. Rio de Janeiro: PTA/ FASE, 1989.

OVERING, Joanna. Elogio do cotidiano: a confiança e a arte da vida social em uma comunidade amazônica. Mana [on line], v.5, n.1. Rio de Janeiro, 1999. Disponível em: $<$ http://www.scielo.br/scielo.php?script=sci_arttext\&pid=S0104-93131999000100004>. Acesso em: 10 fev. 2007.

PASSES, Alan. The value of working and speaking together: A facet of Pa'ikwwné conviviality. In: OVERING, Joanna; PASSES, Alan (orgs). The anthropology of Love and Anger. London: Routledge,2000.

RICHARDS, Paul. Cultivation: Knowledge or performance. In: HOBART, Mark (org.) An Anthropological Critique of development. London and New York: Routledge, 1995.

RICHARDS, Paul. Participatory rural appraisal: a quick-and-dirty critique. In: PLA Notes CD-ROM, London:IIED, 2001.

SEVILLA GUZMÁN, Eduardo; GONZÁLEZ DE MOLINA, Manuel. Sobre a evolução do conceito de Campesinato. São Paulo: Expressão Popular, 2005.

VELHO, Otávio. De Bateson a Ingold: passos na constituição de um paradigma ecológico. Mana [on line], v.7, n.2. Rio de Janeiro, 2001. Disponível em: http:// www.scielo.br/scielo.php?pid=S0034-77012005000100001\&script=sci_arttext. Acessado em 11 fev. 2007.

Recebido em 15 de novembro de 2006.

Aprovado para publicação em 18 de dezembro de 2006.

48 Tércio FEHLAUER; Caroline AYALA. "Agroecologia em terras indígenas"... 